\title{
Digital Platform Regulation in Japan - does the soft approach work?
}

Izumi Aizu

Abstract: With the increasing use of digital platforms, new challenges are growing also in Japan. The areas most visible in this regard are the socio-political, economic, as well as privacy and personal data protection. In the socio-political area, hate speech targeting Korean residents in Japan is most concerning. The negative emotions root in the historical relationship of Japan and Korea. Counteractions by citizens appealed to the international community such as the United Nations that led to a new law, Hate Speech Elimination Act (HSEA) in 2016.

The Act lacks the enforcement tools, but its soft approach has been supplemented by local ordinances and court decisions that effectively reduced hate speech in physical spaces. While hate speech seemed to have migrated to the Internet, the combination of industry self-regulation, a new local ordinance with criminal penalty and an emblematic court decision may be capable to tackle that as well.

The economic concerns around the rise of global Big Tech and increased use of big data and AI drove the enactment of new laws: the Act on Improving Transparency and Fairness of Digital Platforms (AITFDP) in 2021 and the revision of the Act on the Protection of Personal Information (APPI) to be enacted in 2022. Again, the legal approaches are soft, lacking the enforcement tools. However, enhanced capabilities of the Ministries and a new industry self-regulation system are expected to bring a better balance between consumer protection and the digital innovation. This "co-regulation" approach may suit to the Japanese societal structure. It also reflects the multi-stakeholder approach, largely exercised among the Internet Governance concerns.

Keywords: Digital Platform Regulation, Hate Speech, Privacy protection, Personal Data protection, Freedom of Speech, Human rights, Big Tech, Big Data, Co-regulation, Soft and hard approach 
Introduction: Three areas and two approaches to platform regulation

Under the digital platform regulation concerns in Japan, there are three major policy areas:

1) Social and political issues including hate speech, harmful and illegal content, and fake news;

2) Economic concerns including protection of domestic small and medium businesses (SMEs) against Big Tech;

3) Consumer protection including protection of privacy and personal data.

When it comes to regulatory frameworks, two different approaches are observed:

a) Hard approach - use of existing legal framework or establishing a new legislation with strong enforcement;

b) Soft approach - relying on voluntary activities of citizens, local autono$\mathrm{my}$, and industry self-regulation.

This paper will examine these three policy areas and discuss the effectiveness of both hard and soft approaches and their combinations.

A recent book "Hate Speech in Japan: The Possibility of a Non-Regulatory Approach" provides a comprehensive and in-depth analysis of the regulatory approaches of hate speech targeting Korean residents in Japan. ${ }^{1}$ The Author of this paper highly acknowledges the rich knowledge and insights contained in this large volume and would like to examine the value of Japan's non-regulative soft approach that this book puts forward.

\section{Chapter 1. Hate speech regulation in Japan}

This Chapter discusses the regulation on offline and online hate speech in Japan. The hate speech against ethnic Korean residents in Japan has been outstandingly persistent due to their complex historical relationship. ${ }^{2}$ The critical issue has been how to effectively eliminate the hate speech targeting the Korean residents.

1 Shinji Higaki and Yuji Nasu, eds., Hate Speech in Japan (Cambridge: Cambridge University Press, 2021).

2 For the historical background, read references in the Annex. 
Aggressive acts by xenophobic Japanese people toward Korean residents have been present until today. Korean youth in Japan often experience assaults online or in real space. The most visible cases are the direct threats given to Korean students in the street going to their Korean Schools in Japan who wear traditional Korean folk-style outfits called Chima jeogori. They receive such dirty words as "Go home!" or "We will kill you" during commuting on trains. But that is just the tip of the iceberg: Korean residents frequently encounter other hostile acts by some Japanese citizens.

\subsection{Hate speech in 2000 s preceding the new legislation}

The recent strong hate speech activities targeting Korean residents originated in around 2006. They first took the form of public rallies and street demonstration staged by a xenophobic activist group called "Zaitokukai". They claim that Korean residents in Japan are granted special privileges, misinterpreting the meaning of special permanent residency and alleging special welfare and preferential tax treatment, and insist that granting such special privileges to Korean residents in Japan amounts to reverse discrimination against Japanese people. ${ }^{3}$

Their hate speech had such an impact that it became a serious social concern. These activities partly reflected the growing tendency by Japanese public to become more patriotic, or xenophobic, in view of the territorial disputes with Korea over small islands in Sea of Japan. The disputes of historical issues around the so-called "comfort women" during the World War II and the forced labour workers of Koreans under the Japanese Imperial system added fuel to the fire. These disputes are still ongoing and brought over to the court in Korea, and to the public eyes from time to time in Japan, often more visible over the Internet and in social media. Many Korean residents feel threatened, some became furious, all of them got some form of psychological scars.

Zaitokukai's aggressive hate speech in public spaces ignited strong counteractions by the citizens' group of both Korean residents as well as Japanese. It was also brought to the court, that Zaitokukai organized threatening hate demonstrations three times between December 2008 and March 2010 in front of the Kyoto Korean Elementary School and distribut-

3 Shinji Higaki, The Hate Speech Elimination Act, eds. Shinji Higaki and Yuji Nasu (Cambridge: Cambridge University Press, 2021), Chapter, 11, 368, https://doi.org/1 $0.1017 / 9781108669559.012$. 
ed the videos of these demonstrations on YouTube and their website. The school filed a lawsuit against Zaitokukai and the Kyoto District Court ordered to pay about 12 Million Yen for the damages and provided injunction to prohibit further demonstrations in the school neighbourhood in 2013. ${ }^{4}$

In the end, the Supreme Court dismissed Zaitokukai's further appeal in 2014. This is the first case where the Japanese court recognized the illegality of a hate speech based on race or nationality. The Supreme Court concluded: Not only were the acts hate speech in general, but also constituted racial discrimination resulting in serious material damage, based on the International Convention on the Elimination of All Forms of Racial Discrimination (ICERD). ${ }^{5}$

Zaitokukai's demonstration threatening the Kyoto Elementary Korean School was also brought to the criminal court that had preceded the civil case and members of the group were found to be guilty of the interruption of business and insulting action affirmed by the Supreme Court in 2011. ${ }^{6}$

Zaitokukai did not give up, however. In 2015, they tried to attack the Sakuramoto district of Kawasaki City where many Korean residents have been living peacefully with Japanese citizens and forming an extensive network of community activities such as church, nursery school, social welfare facilities and activities to support elderly citizens and persons with disabilities. It is this positive relationship of Korean and Japanese residents that Zaitokukai tried to destroy by staging violent street demonstrations. When the demonstration was attempted, hundreds of local citizens of both Korean and Japanese nationals gathered and blocked the demonstration from entering into the heart of the district. ${ }^{7}$ Zaitokukai tried again later but in no vail.

4 Ryangok Ku, The Current Movement of Hate Speech, eds. Shinji Higaki and Yuji Nasu (Cambridge: Cambridge University Press, 2021), Chapter 5, 203, https://doi.o rg/10.1017/9781108669559.006.

5 Katsuo Yakura, The Legislative Process Leading to the Hate Speech Elimination Act, eds. Shinji Higaki and Yuji Nasu (Cambridge: Cambridge University Press, 2021), Chapter 10, 349, https://doi.org/10.1017/9781108669559.011.

6 Kazushi Ogura, Hate Speech on the Internet, eds. Shinji Higaki and Yuji Nasu (Cambridge: Cambridge University Press, 2021), Chapter, 18, 617 and 631, https:// doi.org/10.1017/9781108669559.019.

7 Kanagawa Shimbun, “ヘイトデモ、我が街に通さず 川崎・桜本“Kanagawa Newspaper, last modified 2015, https://www.kanaloco.jp/news/social/entry-674 17.html. 


\subsection{International voices pushed Japan to the New HSEA}

Given these aggressive anti-Korean campaigns and hate speeches by $\mathrm{Za}$ itokukai and some growing support for them, citizens groups proactively started to lobby both domestic law and policy makers as well as international organisations such as the United Nations Human Rights Council and active NGOs engaged in these policy areas. After they gave them plenty of chances to make their point, the UN Human Rights Committee (HRC) and UN Committee on the Elimination of Racial Discrimination (CERD) concluded with strong recommendations that the Japanese government must take steps to curb hate speeches. ${ }^{8}$

Domestic voices alone were not enough, but these international voices functioned as an extra pressure to the lawmakers, most of them conservative politicians who had been reluctant to act. Thus, the Act on the Promotion of Efforts to Eliminate Unfair Discriminatory Speech and Behaviour against Persons Originating from Outside Japan (known as the Hate Speech Elimination Act, or HSEA), was finally passed on May 24, 2016, as the first law against hate speech in Japan, much sooner than most had expected.

\subsection{The Effect of HSEA challenged}

After two failed attempts, Zaitokukai announced the third attack on Sakuramoto to be held on June 5, 2016, just two days after the new Act (HSEA) was enforced. It was a clear strategic move to deny the practical effectiveness of HSEA. ${ }^{9}$

The local citizens filed a petition that requested a court injunction to prohibit the demonstration. The local court issued an injunction with direct reference to HSEA as well as that of ICERD ratified by Japan and

8 Ayako Hatano, Hate Speech and International Law, eds. Shinji Higaki and Yuji Nasu (Cambridge: Cambridge University Press, 2021), Chapter 3, 105, https://doi.org/10. 1017/9781108669559.004.

9 Toshihide Yamamura, A Chronology of Events and Legislation Related to Hate Speech in Japan, eds. Shinji Higaki and Yuji Nasu (Cambridge: Cambridge University Press, 2021), Appendix A, 723, https://doi.org/10.1017/9781108669559.022. 
Article 14 of Japan's Constitution that prohibits discrimination based on race or other attributes. ${ }^{10}$

There has been no attack by the Zaitokukai's on Sakuramoto since then. A similar case was found in the Shin-Okubo district in Tokyo where Zaitokukai staged several demonstrations, but in the end, they were far outnumbered by the citizens and effectively shut out. ${ }^{11}$

Now, as Hatano asks: "Does the HSEA effectively respond to the recommendations from the UN human rights treaty bodies, as is claimed? Specifically, does it in fact 'internalize' international human rights norms at the domestic level?" 12

HSEA imposes no penalty provisions at all. After defining hate speech as "unfair discriminatory speech and behaviour against persons originating from outside Japan" (Article 2), it prescribes the moral duty of the general public (Article 3) and assigns both central and local governments duties in tracking and eliminating hate speech (Article 4). Articles 5, 6, and 7 provide for measures such as consultation, education, and other awareness campaigns to achieve the goals. ${ }^{13}$ Thus, it provides neither any concrete steps, nor sanctions to enforce the law. Therefore, some remain very doubtful and call for additional provision of penalties; whereas others argue it has a unique value worth to maintain. Ogura argues "it will be subject to interpretation in the civil law courts, and that it may exert certain influence on local government permission or rejection of meetings using public facilities, such as demonstrations and rallies." ${ }^{14}$ Shinji Higaki, the co-editor of the book "Hate Speech in Japan" argues that although the Act lacks the penalty, it "may offer a modest model that strikes an appropriate balance between the freedom of expression and anti-racism." 15 Higaki points out that there are no hate speech laws in the United States either, as the US put absolute value on freedom of expression. ${ }^{16}$

Higaki continues to examine the unique value of the Japanese approach with HSEA.

10 Toru Mori, An Injunction Banning a Xenophobic Group from Demonstrating, Kawasaki Case, eds. Shinji Higaki and Yuji Nasu (Cambridge: Cambridge University Press, 2021) Chapter 14, 493, https://doi.org/10.1017/9781108669559.015.

11 Personal Interview with Mr. Chun Kang Heon, Secretary, Culture Center Arirang in Shin-Okubo district of Shinjuku on May 11, 2021. Mr. Chun is a second generation Zainichi Korean.

12 Ayako Hatano, "Hate Speech and International Law", 115.

13 Shinji Higaki, The Hat Speech Elimination Act, 371.

14 Kazushi Ogura, Hate Speech on the Internet, 624.

15 Shinji Higaki, The Hat Speech Elimination Act, 366.

16 Shinji Higaki, The Hat Speech Elimination Act, 365. 
"Under current circumstances, hate speech regulation must be implemented deliberately in Japan. The HSEA may be a second-best way of preventing hate speech, at the very least, but it may be the most suitable model of hate speech law in the world." [emphasis added by the Author] "There are several points that we might highlight as its strengths of the HSEA. First, it respects the 'marketplace of ideas', which is based on the fundamental principles of modern law, such as freedom, autonomy, and self-realization. Second, numerous works on hate speech have argued that the criminal regulation of public discourse will cause undesirable backlash, produce martyrs, or drive dangerous speech underground, but the Japanese non-regulatory model is immune to these problems." 17

The Author considers that Higaki's high evaluation of HSEA and Japanese model is too optimistic, especially describing it as "the most suitable model in the world", since different societies have different structures and historical and cultural contexts, and therefore no model could work "best" singlehandedly. Yet, as Higaki points out, the respect for "market of ideas" and avoiding undesirable backlash are worth to acknowledge as the merits of HESA.

\subsection{Hate Speech on the Internet}

After HSEA was established, the Zaitokukai's aggressive hate speech activities seemed to have subsided greatly. HSEA is seemingly working to suppress hate speech in the physical space. However, expressions of hate speech have not entirely vanished. There are still many manifestations of hate speech on the Internet as of today. The centre of gravity has shifted from the offline to the online world. Clearly, the Internet and social network services (SNS) on digital platforms are widely used to spread and amplify hate speech. Kazushi Ogura points out that there is significant co-relation between "offline" and "online" hate speech activities as follows.

The cases that follow are not cases of discriminatory expressions simply being posted on the Internet but are examples of public demonstrations or rallies that have taken place in offline contexts and have

17 Shinji Higaki, The Hat Speech Elimination Act, 379. 
subsequently been filmed, photographed, and uploaded to video-sharing sites. ${ }^{18}$

Hate speech on the Internet has been present in Japan since the early days of Internet use started in the 1990s. As the use of the Internet has grown, the amount of hate speech has increased exponentially. The Internet's potential to hide the identity, the low barrier to send offensive messages to the Internet or SNS, and the easy amplification by copying and spreading these messages are relevant factors.

In addition to targeting Korean residents, there are also aggressive assaults against other ethnic minorities such as Chinese residents as well as expat workers mostly from the developing countries in Asia, Middle East, and South America. But the author believes it is fair to say that the hate speech towards Korean residents has been the most vocal and problematic in Japanese society.

The Human Rights Bureau of the Ministry of Justice published a survey report on the foreign residents in Japan in 2017. The respondents were of many nationalities including Chinese (32.5\%), South Korean (22.1\%), the Philippines (6.7\%), Brazilian (5.2\%), Vietnamese (4.8\%) and others. North Koreans was only $1.4 \%$. They did not include Japanese nationals who have foreign origins such as Korean Japanese. ${ }^{19}$

In this report, $41.6 \%$ of the 3,400 respondents answered that they have seen discriminatory messages on the Internet against foreign residents in Japan. 33.3\% of them answered that they have seen hate speech actions such as street demonstrations or rallies against them over the Internet, while $42.9 \%$ answered that they have seen them on newspapers or TVs. $65 \%$ of them answered that they felt uncomfortable, while $19 \%$ said these should not be allowed, 22\% felt threatened and only $7 \%$ answered they did not feel much. ${ }^{20}$

Clearly, hate speech on the Internet still has negative impacts to foreign residents in Japan. While the general level of emotions against foreigners has not increased that much, in part due to various efforts including the

18 Kazushi Ogura, Hate Speech on the Internet, in: Hate Speech in Japan (Cambridge, Cambridge University Press, 2021), Chapter 18, 614.

19 Center for the Promotion of Human Rights Education and Encouragement, 外 国人住民調査報告書一訂正版. (FY Center for the Promotion of Human Rights Education and Encouragement, 2017), 8, http://www.moj.go.jp/content/00122618 2.pdf.

20 Center for the Promotion of Human Rights Education and Encouragement, 外国 人住民調査報告書一訂正版, 45 . 
provision of HSEA and other institutional measures, hate speech on the Internet remains as a very serious problem.

The HSEA does not specifically mention the Internet or any electronic means. However, in the supplementary resolutions of the parliament the clause implement countermeasures to deal with individuals or groups promoting unjustifiable discriminatory expression against persons from overseas or from outside Japan and to eliminate acts that promote unfair discriminatory behaviour on the Internet' is mentioned as an issue for special consideration. This indicates the problematic nature of the Internet with regard to harmful content. ${ }^{21}$

Nevertheless, today, in 2021, concerns on social and political dimensions of the platform regulation, especially on hate speech and free speech issues are not that high. This does not mean that there are no issues at all, but the general awareness among the Japanese public about the hate speech has become quite low compared with five to ten years ago.

\subsection{Industry self-regulation on Internet content}

While the explicit scope of HSEA remains outside of the online space, industry self-regulation on the illegal and harmful content in general in voluntary manner has been implemented over the past 20 years.

In 2001, to regulate the illegal and harmful content on the Internet, the Act on the Limitation of Liability for Damages of Specified Telecommunications Service Providers and the Right to Demand Disclosure of Identification Information of the Sender, or the "Provider Liability Limitation Act" in short, was established. This Act helps deleting illegal and harmful material posted over the Internet, yet it only provides the procedural guidelines, and not for not legally binding duties, showing a soft approach again.

When an internet service provider is either requested to delete content that is illegal or harmful by any subject or to disclose the name and contact information of such senders by following the Act, their liabilities will be immured. When providers are asked by "trusted parties" such as a lawyer or the police defined in their voluntary code, they will share the IP address of the sender, but not the identity information. The providers will submit the sender's identity information only when they are asked by a legitimate court order. The reason behind this cautious process is

21 Kazushi Ogura, Hate Speech, 613. 
that the Japanese Constitution Article 21 explicitly protects the "secrecy of communication." 22

There is a "model contract article" jointly published by four Internet related industry associations which sets a standard model of contract article with their customers. Many providers are using this model contract to prohibit defamation, discrimination, and other offensive acts, and to delete certain messages unilaterally without the sender's consent. After the HSEA was enacted in 2016, this model was revised in 2017 adding languages that define hate speech. Irrespective of using this model contract or not, most major commercial providers publish their own contract that explicitly prohibits the posting of material that promotes hate speech and actions. Yahoo! Japan and Twitter Japan are examples of such providers. ${ }^{23}$

\subsection{Local ordinances implemented}

With institutions such as the Human Rights Bureau of the Ministry of Justice, the administrative branch of the government is engaged in providing remedy for damages caused by human rights violations including hate speech on the Internet. ${ }^{24}$ Several local governments are also working on other actions to prevent and delete hate speech, most visibly in the form of issuing a local ordinance against hate speech. The City of Osaka and Kawasaki are leading in this regard as they have a large community of Korean residents.

In 2016, the Osaka City Ordinance to Deal with Hate Speech was established in Osaka. This ordinance deals with instances in which Osaka citizens or organizations suffer damage because of the diffusion of hate speech, including ones via Internet, in or around Osaka City, and citizens - or the mayor of the city of Osaka - may request that steps be taken to curb hate speech. ${ }^{25}$

In July 2020, Kawasaki City established an Ordinance on Establishing a City with No Discrimination and Respecting Human Rights. What is

22 Prime Minister of Japan and His Cabinet, The Constitution of Japan, 1947, https://j apan.kantei.go.jp/constitution_and_government_of_japan/constitution_e.html

23 Human Rights Protection Committee of Daini Tokyo Bar Association, "Internet and Hate Speech (in Japanese)" (Gendai Jimbunsha, 2019), 14.

24 Human Rights Protection Committee of Daini Tokyo Bar Association, "Internet and Hate Speech (in Japanese)", 15.

25 Kazushi Ogura, Hate Speech in Japan, in: "Hate Speech on the Internet", Chapter 18, 625. 
unique about this ordinance is that this is the first case where the criminal punishment including financial penalty is included in the official regulation. Hate speech over the Internet had been excluded from criminal punishment since the authority considered the balance between freedom of expression and hate speech. In both cases, the civic groups' active engagement and lobbying played vital roles. ${ }^{26}$

Under this ordinance, a citizen could request the City to become a proxy of him/her so that the City makes the formal request to the Internet Service Provider of taking down the offensive material from the Internet space. Ms. Che Kainjya who is a third-generation Korean living in Kawasaki City filed a lawsuit against the city to request deletion of offensive tweets in 2020. However, it took five months to investigate through a third-party review board who recognized only two tweets out of 332 as offensive. ${ }^{27}$ There is no information available as to the basis of this judgement, but the author speculates that the review board weighed the freedom of expression for many of the tweets which had some vagueness in their texts.

Thus, even though citizens' active engagements are pushing the local governments, the case in Kawasaki illustrates the difficulty to materialize an effective solution over hate speech on the Internet in practice.

As mentioned above, hate speech has been included in the industry self-regulation framework. There are several cases reported where Korean residents who used the disclosure procedure of the self-regulation model won compensation payment in the court for having their dignities damaged or defamed. ${ }^{28}$

The latest case was reported on May 13, 2021. The Tokyo High Court ordered a man to pay 1.3 million yen in damages for posting discriminatory comment about Korean residents on his blog. "The posted comments were extremely vicious," presiding Judge Yukio Shirai said, adding that racial discrimination is illegal per se.

The damage's amount is unusually high for comments made via a single post, and it is expected to have a deterrent effect on hate speech, the plaintiff's lawyer said. The plaintiff obtained the identity of the man who

26 Naoto Higuchi, ibid., in Chapter 16 “Japan’s Postcolonial Hate Speech” 546.

27 Joji Mochida, “へイトスピーチは止まったか：川崎市が全国初の罰則付き条 例” Nippon.com, November 12, 2020, https://www.nippon.com/ja/in-depth/d0 0648/.

28 Human Rights Protection Committee of Daini Tokyo Bar Association, "Internet and Hate Speech (in Japanese)" (Gendai Jimbunsha, 2019), 11. 
posted these insulting comments by asking the Internet service provider involved to disclose it. ${ }^{29}$

Since HSEA's text only protects the right of specific individuals, excluding collective term such as race or nationality, some general or abstract expressions such as "Koreans go home" or "kill them" had not been regarded as the subject of this Act. ${ }^{30}$ However, this latest court ruling suggests that such comments are largely illegal. The judge took the spirit of the Act, not the letter, and recognized that they hurt the plaintiff's personal rights and constitute racial discrimination.

This latest ruling is expected to bring further potential to reduce hate speech on the Internet. But it may still require active engagement of citizens who dare to file suits in the court.

\subsection{Political and Social areas}

In addition to hate speech, offensive speech, fake news, mis-information campaigns, cyber-bullying, and communication fraud, all are persistent problems in Japan's digital media at large.

In Japan, the use of an online medium and SNS for political purposes is neither so widely exercised nor so influential as that of the United States or Korea. There is an Election Law that strictly limits the use of email services during the public election period. Only the officially recognized candidates and registered political parties can send emails calling for voting to their candidates. Unsolicited bulk emails calling for voting for a specific candidate or party is prohibited; candidates and parties who plan to send such campaign emails are mandated to obtain the consent of the addressees in advance in opt-in or opt-out manner.

Moreover, the general public is not that much interested in or affected by the use of these electronic media for political campaigns. ${ }^{31}$ Therefore, the room for fake news or misinformation aimed to attack the opposing candidates is relatively small, which is why such methods are much less practiced than in some other countries.

29 “Tokyo court orders Oita man to pay $¥ 1.3$ million in damages over 'vicious' racist comments against boy", the japan times, May 13, 2021, https://www.japantimes.co. $\mathrm{jp} /$ news/2021/05/13/national/crime-legal/tokyo-court-ruling-racist-comments/.

30 “Internet and Hate Speech", 13.

31 "Japan's first 'Internet election”, the japan times, July 10, 2013, https:/www.japant imes.co.jp/opinion/2013/07/10/editorials/japans-first-internet-election/. 
Of course, there still exist diverse kinds of offensive messaging and other online activities that could defame, offend, or provide fake news and mis-information in public. We have not yet observed well-organized online negative campaigns so far; they are mostly spontaneous and solitary ad hoc reactions and casual criminal acts for fun until today.

There is some hate speech and offensive speech against sexual, ethnic, and social minorities of various dimensions, but again they are less organized and more personal in general except in the case of hate speech against Koreans and also against Burakumins. Burakumins are ethnic Japanese people who were historically discriminated and still are targets of online hate speech. It is also a very serious and long-standing human rights violation issue in Japan. ${ }^{32}$

On the individual level, offensive bullying among juveniles, for example, or vicious speeches related to domestic violence using the Internet are often observed, and they have led to suicide or homicide cases at worst. Sexual seductions, illegal drug sales, and other anti-social uses of online media also exist and sometimes promoted by organized criminal groups. Phone or communication fraud, especially targeting the senior citizens, by these criminal groups are rather serious and widespread.

Most large SNS platform operators are requested to monitor criminal use of their services, with varying degrees of regulatory mechanisms. Child pornography and direct seduction for committing suicide are strictly prohibited and could legally be filtered out online, while other forms of offensive or illegal messages are regulated on a more voluntary basis including "Notice and Takedown" process or legal measures in the court.

A new wave of fake news and misinformation was observed in 2020 with the outbreak of the COVID-19 pandemic in Japan. People had difficulties in finding accurate information, and a loft of false information that came from outside Japan was translated into Japanese and led to confusion. The government took some action and asked Internet platform providers such as Google and LINE to take measures to send notices of caution automatically once the term "Corona virus" was found in any use of online instances.

In any case, the issue of how to strike a balance between conflicting values such as freedom of expression vs. hate speech remain important, and we will examine the effectiveness of hard and soft approaches after

32 The Headquarters of Buraku Liberation league, "What is Buraku Discrimination?" Last modified: Dec 25, 2005 http://www.bll.gr.jp/en/index.html. 
discussing other areas of digital platform regulation approaches in the next Chapter.

\section{Chapter 2: Privacy and Personal Data Protection and Economic Concerns}

\subsection{Economic concerns}

The second area of digital platform regulation is the one of economic concerns. Referring to this, the obvious concerns are aimed at the excessive power and behaviours of the global Tech Giants such as Google, Amazon, Facebook, and Apple. Policy makers in Japan have been taking these concerns seriously for the past years and now they are starting to put some institutional measures to regulate the excessive behaviours on the digital platforms in domestic markets. Even though it is difficult to place a regulatory framework directly upon this challenge, the new platform regulation enacted in February 2021 can be interpreted as such a manifestation.

The global rankings of the market cap of large corporations are often referred to as the indicator of the economic strength (and weakness). In 1989, there were six Japanese companies among the global top ten as shown in the table. After more than three decades, there are no Japanese companies in the top ten in 2021, while all top five are American Big Tech companies with strong digital platform services, one from China, Alibaba, is also offering platform services, and one from Taiwan, TSMC, is supporting these digital platform infrastructures with its huge supply of semiconductors.

Table 1. Most Valuable Global Companies in $1989^{33}$

\begin{tabular}{|l|l|l|l|}
\hline Rank & Company & Country & $\begin{array}{l}\text { Full Market Cap } \\
\text { (in USD M) }\end{array}$ \\
\hline 1 & Industrial Bank of Japan & Japan & $104,291.49$ \\
\hline 2 & Sumitomo Bank & Japan & $73,304.65$ \\
\hline 3 & Fuji Bank & Japan & $69,403.38$ \\
\hline 4 & Dai-Ichi Kangyo Bank & Japan & $64,036.45$ \\
\hline 5 & Exxon Corp & United States & $63,838.00$ \\
\hline
\end{tabular}




\begin{tabular}{|l|l|l|l|}
\hline 6 & General Electric USA & United States & $58,187.00$ \\
\hline 7 & Tokyo Electric Power & Japan & $56,499.62$ \\
\hline 8 & IBM Corp & United States & $55,656.99$ \\
\hline 9 & Toyota Motor Corp. & Japan & $53,251.22$ \\
\hline 10 & American Tel \& Tel & United States & $48,951.00$ \\
\hline
\end{tabular}

Table 2. Most Valuable Global Companies in $2021^{34}$

\begin{tabular}{|l|l|l|l|}
\hline Rank & Company & Country & $\begin{array}{l}\text { Full Market Cap } \\
\text { (in USD Bn) }\end{array}$ \\
\hline 1 & Apple & United States & $2,226.60$ \\
\hline 2 & Microsoft & United States & $1,901.40$ \\
\hline 3 & Amazon & United States & $1,660.00$ \\
\hline 4 & Alphabet (Google) & United States & $1,591.30$ \\
\hline 5 & Facebook & United States & 904.7 \\
\hline 6 & Berkshire Hathaway & United States & 664.8 \\
\hline 7 & Tesla & United States & 647.7 \\
\hline 8 & Alibaba & China & 610.8 \\
\hline 9 & $\begin{array}{l}\text { Taiwan Semiconductor } \\
\text { Mfg. Co. (TSMC) }\end{array}$ & Taiwan & 605.9 \\
\hline 10 & Visa & United States & 495.1 \\
\hline
\end{tabular}

With the sophisticated use of enormous amounts of online data and high capability of analysing and utilizing them with latest AI technologies, the Big Tech companies now have dominant positions in the global digital economy. The fear against the Big Tech companies can be considered as the strongest factor for the Japanese government to establish a new regulatory framework over the Digital Platform operators.

33 Steiger, Paul E., "What a difference 25 years makes", CNBC, April 29, 2014, https://www.cnbc.com/2014/04/29/what-a-difference-25-years-makes.html.

34 Dogs of the Dow, s.v. "Largest Companies by Market Cap Today", accessed June 4, 2021, https://www.dogsofthedow.com/largest-companies-by-market-cap.htm. 


\subsection{The formation process of the "Act on improving Transparency and Fairness of Digital Platform"}

The Government initiated the policy discussion on digital platform regulation in 2018. The first action that led to establish the new rules to regulate the digital platformers was called for by the "Investments for the Future Strategy 2018", that was formally adopted by the Cabinet under the leadership of Prime Minister Shinzo Abe in June 2018. ${ }^{35}$ This strategy mandated the government to formulate the basic design rules that guide the implementation of the regulatory framework by December 2018. Under this mandate, three agencies were engaged to analyse and implement the proper legal instruments aimed to provide a fair and effective regulatory framework for the digital platformer operations. ${ }^{36}$

In Japan, when a new regulatory framework is proposed, it is almost standard to designate one government agency in charge in general. In the case of digital platform regulation however, three agencies were assembled to cooperate. This is highly unusual and illustrates how complex the issue could be.

Hence the Ministry of Internal Affairs and Communications (MIC), Ministry of Economy, Trade, and Industry (METI), and Japan Fair Trade Commission (JFTC) are formally engaged. A basic design rule for setting the regulatory framework for digital platform operators were agreed. Those basic rules consisted of the following seven elements:

1. Legal evaluation viewpoints of digital platform operators

2. Promotion of proper development of digital platform operators

3. Establish transparency to ensure the fairness of digital platform operators

4. Establish fair and free competition among digital platform operators

5. Consider the rules for data portability and openness

6. Implement the balanced, flexible, and effective rules

7. Consider the international enforcement and harmonization method

35 Prime Minister and his Cabinet, Joint Meeting of the Council on Economic and Fiscal Policy and the Council on Investments for the Future (Cabinet Public Relations Office, 2018),

https://japan.kantei.go.jp/98_abe/actions/201806/_00039.html.

36 Prime Minister and his Cabinet, Future Investment Strategy 2018 (Draft), (Cabinet Public Relations Office, 2015), http://www.kantei.go.jp/jp/singi/keizaisaisei/dai28/ siryou1.pdf. 
In January 2019, the JFTC conducted a comprehensive research on the existing practices of the digital platform operators and came out with the Interim Report in April $2019^{37}$ and the Final Report in October 2019. ${ }^{38}$ This Final Report first provided the overview of the "digital platform" in our socio-economic life, emphasizing their strong positive impacts with innovations, analysing their "double-sided market nature" and "network effect" as well as "low marginal costs" and "the economy of scale" in economic terms. It further points out that digital platforms could produce enormous benefits with highly efficient use of large data, while they may also offer potential over-concentration to a few platform operators and may lead to monopolies or oligopolies and result in lock-in effects due to the high switching costs.

The Report continued to share concerns around competition policies, such as abuse of dominant position, exclusion of other platform operators, exclusion of competitive business users, and unfair coupling of digital platform operators to stifle competition. Based on research, this report highlighted some of the unfair practices found, such as unilateral change of rules by the dominant platform operator, unfair treatments, and excessive burden of shipping costs imposed to small and medium business users by the platform operators, or exclusive restrictions over competitive services by app platform operators. It also pointed out the potential abuse of transaction data by the platform operators; unfair treatments of business users by the operators, unilateral enforcement of "Most Favoured Nation status" or product pricing.

They also addressed the need for new mechanisms in addition to the aggressive enforcement of the existing anti-trust legal framework. Adopting the anti-trust laws with ex-post enforcement such as an exclusion order or penalty would require strict due process that may not be able to provide timely, flexible, and effective relief required for regulating the business practices over the new digital platforms. As for the methodology of the regulation, a "co-regulation" approach was proposed that would allow the voluntary effort of private sector players which will be supplemented by abstract codes and principles set by the law.

37 Japan Fair Trade Commission, "Interim report regarding trade practices on digital platforms", Japan Fair Trade Commission, last modified 2019, https:/www.jftc .go.jp/en/pressreleases/yearly-2019/April/190417.html.

38 Japan Fair Trade Commission, "Report regarding trade practices on digital platforms (Business-to-Business transactions on online retail platform and app store)", Japan Fair Trade Commission, last modified 2019, https://www.jftc.go.jp/en/press releases/yearly-2019/October/191031.html. 


\subsection{Act on Improving Transparency and Fairness of Digital Platforms (AITFDP) enacted}

It took two years to pass the new law "Act on Improving Transparency and Fairness of Digital Platforms (AITFDP)." 39 Under this Act, digital platform providers that meet the criteria stipulated under the Cabinet Order are obliged to disclose terms and conditions of trading, secure fairness in operating digital platforms, submit a report on the current situation of business operation with self-assessment every fiscal year. The government under the Minister of Economy, Trade, and Industry then makes an assessment of this report and publicizes the results.

The Act obligates METI to establish a system in which METI should request the JFTC to exercise certain measures under the Antimonopoly Act if METI finds any cases violating the Antimonopoly Act. The new Act also requires specified digital platform providers to give prior notices of any change thereof to the platform users. ${ }^{40}$ The new Act sets the annual revenue in Japan as the benchmark to designate these platform players under the regulatory subject as specified providers.

In February 2021, five such specified operators are announced by the government. The first group consists of Amazon Japan, Rakuten and Yahoo! who offer comprehensive online services such as e-commerce sales, travel, banking and security services, as well as other numerous online services, making more than 300-billion-yen (USD 3bn) revenue per year. The second group consists of Apple and Google as mobile application providers or app stores with more than 200-billion-yen (USD 2bn) annual turnover. ${ }^{41}$

The obligations for the specified operators seem light:

i) disclose terms and conditions of trading, secure fairness in operating digital platforms,

39 Ministry of Economy, Trade and Industry, Cabinet Decision on the Bill for the Act on Improving Transparency and Fairness of Digital Platforms (Tokyo, Ministry of Economy, Trade and Industry, 2020), https:/www.meti.go.jp/english/press/2020/ 0218_002.html.

40 "Japan's new law regulating tech giants' commerce platforms takes effect", the japan times, February 1, 2021, https://www.japantimes.co.jp/news/2021/02/01/busi ness/tech/tech-giant-law-takes-effect/.

41 "Summary of a Bill on Improving Transparency and Fairness of Specifies Digital Platforms", https://www.kantei.go.jp/jp/singi/digitalmarket/pdf_e/documents_20 0218.pdf. 
ii) submit a report on the current situation of business operation with self-assessment,

iii) give prior notices of any change thereof to the platform users. However, since "fairness" is not explicitly defined in this Act, there is room for interpretation and evaluation by the government.

If the METI Minister finds the report and its assessment not fair and publicly announces this, the operator will have to be voluntarily forced to change their terms and conditions in their own languages.

In other words, the government would not say "do this or do that", but the operators themselves must judge how to satisfy the government, and the public. This could be more difficult sometimes than to follow the explicit rule.

As the language of the new Act indicates, there is little room for strong enforcements but mostly voluntary actions to meet rather vague terms of "disclose information" and "secure fairness." This is very much the same approach as other Acts on Platform regulations, like the Act for Elimination of the Hate Speech or Act on the Protection of Personal Information (APPI).

\subsection{Privacy and Personal Data protection}

The third area of the policy concerns is of privacy and personal data protection. One of the challenges of establishing proper protection of personal data in Japan has been that there was no single unified regulatory system at work. The Act on the Protection of Personal Information (APPI) was established in 2003, but its narrowly segmented sectoral approach had been problematic with a large part of its implementation in practice left to each industry sector and their corresponding ministries.

To overcome these shortcomings of APPI, the Personal Information Protection Commission (PPC) was established as a central agency to manage the regulatory system under APPI in 2016 to provide the protection of the rights and interests of individuals while taking into consideration proper and effective use of personal information including "My Number", a national ID system for citizens. The PPC is an "independent organ in the Japanese legal framework." 42 The PPC has been working to improve the

42 Personal Information Protection Commission, "Personal Information Protection Commission”, last modified 2016, https:/www.ppc.go.jp/en/. 
regulatory system and several revisions of the APPI have been implemented.

In 2020, the APPI received a major revision to cope with the increased use of digital data especially by the digital platform operators applying highly sophisticated "big data" and AI related technologies. ${ }^{43}$ This new trend has created challenges for citizens to grasp the way their own rights are protected/infringed in advance. Thus, the new revisions tried to enhance protection for the individual rights including information disclosure proceedings, added obligations for business operators to include short-term data as the subject to protect and preserve, and electromagnetic (digitized) data was added as the form of information disclosure.

The benefits for business operators were also considered and the new articles on anonymous and pseudonymous information were added to the APPI that allow anonymously processed data to be shared by the third party, but not the pseudonymously processed data in general.

The gap between the central government and the local municipalities in terms of regulatory harmonization was also a big problem. There are more than 1,700 local governments in Japan that all have different rules or ordinances for the personal data protection procedures.

Now, the passage of the new package of digital reform laws on May 12, 2021 included the APPI's revision to close that gap. ${ }^{44}$ The government now claims that Japan's personal data protection procedures will be streamlined across national and local governments and will have much higher efficiency for the benefit of all. However, some consumer advocates fear that the respect for privacy and human rights, which are often given higher priorities in local ordinances, may be compromised in the interest of the business use of the personal data once they are all unified under the new national system. ${ }^{45}$

43 Personal Information Protection Commission, "Promulgation of the Amendment Act of the Act on the Protection of Personal Information, etc.", last modified 2020, https:/www.ppc.go.jp/en/news/archives/2020/20200618/.

44 "Japan passes laws to set up digital policy agency in September", Nikkei Asia, May 12, 2021, https://asia.nikkei.com/Politics/Japan-passes-laws-to-set-up-digital-policy -agency-in-September.

45 “どうなる? “個人情報保護制度”「デジタル改革関連法」成立”, NHK, May 12, 2021, https://www3.nhk.or.jp/news/html/20210512/k10013026561000.html. 


\subsection{Transfer of personal data to a foreign country}

It has been very difficult to regulate the use and transfer of personal data outside the jurisdiction. There is a strong concern that the global Big Tech, Google, Amazon, Facebook and Apple, for example, are collecting huge amounts of personal data via transaction, posting, or various forms of information search and retrieval and utilize them with effective advertising and sales beyond national regulatory control.

To cope with these challenges, the revision of the APPI in 2020 also added new restrictions on transfer of personal data to a third party in a foreign country. Yet these revisions will only become effective in 2022 and the details of new rules were not yet announced from the PPC thus creating ambiguous reactions from both consumer groups and the business community.

\subsection{Tentative Conclusion}

Since the Act on Improving Transparency and Fairness of Digital Platforms (AITFDP) has just been enforced in February 2021, it remains to be seen how effective the new regulatory framework will be. Some are again sceptical as the language is vague and basic, and they doubt it has any real effect of bringing the Japanese players on par to the Big Tech, which is the original aim of the policy and the strategy of the government and industry.

Prof. Takanori Ida of Kyoto University who is also the Chair of the Cabinet Working Group on Digital Market Competition Council said that the AITFDP adopted the "co-regulation" approach where the government set the basic framework while the details were left to the creativity and wills of the private sector. They are now starting to discuss the possible co-regulation on the Digital Advertising market as the third area of digital platform regulation. ${ }^{46}$

The Author believes that while this soft approach will not bring an immediate effect of making Japanese corporations viable in the global digital platform marketplace, it may urge the companies and their management to become more serious and aggressive in executing their business innovations that may take longer but produce more concrete outcomes.

46 Takanori Ida, "New competition law for the digital platformers", in: Horitsu no Hiroba (Legale Square), Tokyo, Gyosei, May 1, 2021 
The protection is one thing, self-reliance and bold moves are another. Strong will and commitment to the excellence should be, regardless of the amount of time it might take, placed as the core of the economic and political strategy Japan should undertake.

If we stood for the citizens' benefits, should we look for strict regulations and explicit enforcement mechanisms including heavy penalties, once the actions of a business enterprise or of a xenophobic group are found illegal?

In the case of HSEA, the financial penalty in national law may not be the most effective way to eliminate the root cause of the problem. It is the responsibility of citizens, who find these hate actions destructive to our society, to start campaigns against them and the stronger their voices are, the more effectively they can stop the undesired actions. The law merely "allows" or encourages these voices to be heard, and it clearly indicates where justice may be found.

These "co-regulation" approaches may suit Japan's social structure in the most productive way. They can also be seen as taking the multi-stakeholder approach, largely exercised among the Internet Governance policy circles.

\section{Bibliography}

Ayako Hatano, Shinji Higaki and Yuji Nasu. Hate Speech and International Law. Cambridge. Cambridge University Press: 2021. https://doi.org/10.1017/9781108 669559.004 .

Center for the Promotion of Human Rights Education and Encouragement. 外国 人住民調査報告書一訂正版. 2017. http://www.moj.go.jp/content/001226182.p df.

Dogs of the Dow, s.v. "Largest Companies by Market Cap Today". https://www.dogs ofthedow.com/largest-companies-by-market-cap.htm.

Gang, Deogsang. "Kanto Daishinsai (Kanto Great Earthquake)”. Tokyo: Chuo-Koronsha, 1975.

Human Rights Protection Committee of Daini Tokyo Bar Association. Internet and Hate Speech. Gendai Jimbunsha. 2019.

Japan Fair Trade Commission. Interim report regarding trade practices on digital platforms Japan Fair Trade Commission. https://www.jftc.go.jp/en/pressreleases/ yearly-2019/April/190417.html.

Japan Fair Trade Commission. Report regarding trade practices on digital platforms (Business-to-Business transactions on online retail platform and app store). Japan Fair Trade Commission, 2019. https://www.jftc.go.jp/en/pressreleases/yearly-2019/Oc tober/191031.html. 
Jiji, Kyodo. "Japan's new law regulating tech giants' commerce platforms takes effect”. the japan times, February 1, 2021. https://www.japantimes.co.jp/news/202 1/02/01/business/tech/tech-giant-law-takes-effect/.

Jiji, Kyodo. "Tokyo court orders Oita man to pay $¥ 1.3$ million in damages over 'vicious' racist comments against boy”. the japan times. May 13, 2021. https://ww w.japantimes.co.jp/news/2021/05/13/national/crime-legal/tokyo-court-ruling-raci st-comments/.

Joji Mochida. “へイトスピーチは止まったか：川崎市が全国初の罰則付き条例” Nippon.com, November 12, 2020. https:/www.nippon.com/ja/in-depth/d00648/.

Katsuo Yakura, Shinji Higaki and Yuji Nasu. The Legislative Process Leading to the Hate Speech Elimination Act. Cambridge: Cambridge University Press, 2021. https://doi.org/10.1017/9781108669559.011.

Kazushi Ogura, Shinji Higaki and Yuji Nasu. Hate Speech on the Internet. Cambridge: Cambridge University Press, 2021. https://doi.org/10.1017/978110866955 9.019 .

Kyodo. "Japan passes laws to set up digital policy agency in September". Nikkei Asia. May 12, 2021. https://asia.nikkei.com/Politics/Japan-passes-laws-to-set-up-di gital-policy-agency-in-September.

Malina Andreia Pal. "The Japanese invasions of Korea: who was the real winner of the Imjin war?” January 2020, Geneva. https://www.researchgate.net/publication /344072575_The_Japanese_invasions_of_Korea_who_was_the_real_winner_of_t he_Imjin_war.

Ministry of Economy, Trade and Industry. Cabinet Decision on the Bill for the Act on Improving Transparency and Fairness of Digital Platforms. Tokyo: Ministry of Economy, Trade and Industry, 2020. https://www.meti.go.jp/english/press/2020/ 0218_002.html.

Park Eun-sik. “韓国独立運動の血史 “The Bloody History of the Korean Independence Movement”. (Heibonshya, 1972).

Personal Information Protection Commission. "Personal Information Protection Commission". https:/www.ppc.go.jp/en/.

Personal Interview with Mr. Chun Kang Heon. Secretary. Culture Center Arirang in Shin-Okubo district of Shinjuku on May 11, 2021.

Prime Minister and his Cabinet. Future Investment Strategy 2018 (Draft). Tokio: Cabinet Public Relations Office. 2015. http://www.kantei.go.jp/jp/singi/keizaisai sei/dai28/siryou1.pdf.

Prime Minister and his Cabinet. Joint Meeting of the Council on Economic and Fiscal Policy and the Council on Investments for the Future. Tokio: Cabinet Public Relations Office, 2018. https://japan.kantei.go.jp/98_abe/actions/201806/00039. html.

Ryangok Ku, Shinji Higaki and Yuji Nasu. The Current Movement of Hate Speech. Cambridge: Cambridge University Press, 2021. https://doi.org/10.1017/9781108 669559.006.

Shimbun, Kanagawa. “へイトデモ、我が街に通さず 川崎・桜本”. Kanagawa Newspaper, 2015. https://www.kanaloco.jp/news/social/entry-67417.html. 
Shinji Higaki and Yuji Nasu, eds. Hate Speech in Japan. Cambridge: Cambridge University Press, 2021.

Steiger, Paul E. "What a difference 25 years makes“. CNBC, April 29, 2014. https:// www.cnbc.com/2014/04/29/what-a-difference-25-years-makes.html

Takanori Ida, "New competition law for the digital platformers" in Horitsu no Hiroba (Legale Square), Tokyo, Gyosei, May 1, 2021.

The Headquarters of Buraku Liberation league. "What is Buraku Discrimination?" Last update: Dec 25, 2005 http://www.bll.gr.jp/en/index.html.

Toru Mori, Shinji Higaki and Yuji Nasu. An Injunction Banning a Xenophobic Group from Demonstrating, Kawasaki Case. Cambridge: Cambridge University Press, 2021. https://doi.org/10.1017/9781108669559.015.

Toshihide Yamamura. A Chronology of Events and Legislation Related to Hate Speech in Japan. eds. Shinji Higaki and Yuji Nasu (Cambridge: Cambridge University Press, 2021), Appendix A, 723, https://doi.org/10.1017/9781108669559.022.

Ooba, Yasunori. "Zainichi Kankoku and Chosenjin (South and North Korean residents in Japan”. Chuokoron Shinsha. 1993.

“Japan's first 'Internet election”. the japan times. July 10, 2013. https://www.japanti mes.co.jp/opinion/2013/07/10/editorials/japans-first-internet-election/.

Shinji Higaki. The Hat Speech Elimination Act. eds. Shinji Higaki and Yuji Nasu. Cambridge: Cambridge University Press, 2021. Chapter, 11, 368, https://doi.org/ 10.1017/9781108669559.012.

"Summary of a Bill on Improving Transparency and Fairness of Specifies Digital Platforms”. https://www.kantei.go.jp/jp/singi/digitalmarket/pdf_e/documents_2 00218.pdf.

“どうなる? “個人情報保護制度”「デジタル改革関連法」成立”. NHK, May 12, 2021. https://www3.nhk.or.jp/news/html/20210512/k10013026561000.html.

\section{Annex: Historical Relationship between Japan and Korea}

Average Japanese people today have very little knowledge of the history between Japan and Korea. The history with neighbouring Asian countries has been largely excluded in the formal school education, especially that of the modern history.

The following is a very short summary of major topics that may help to understand some unfortunate and conflicting elements, as the basic factors that led the hate speech attitudes of some Japanese and the counter-reactions of many Korean residents in Japan. 


\section{A.1. Ancient age to Middle Age}

There is evidence that certain parts of the primitive Japanese culture and society were shaped by the people who migrated from Korean Peninsula to Japanese archipelago in the ancient age. Hence there are many similarities in both cultures.

The first hostile or discriminatory attitudes of Japanese people against Koreans can be found in the feudal era when the ruler Toyotomi Hideyoshi launched two military invasions to Korean Peninsula in 1592 and in 1598. Both battles resulted in an ultimate retreat of Japan's army, but the cruel acts of Japanese warriors to Korean civilians are well known and remembered among the Korean people. ${ }^{47}$

After the Meiji Restoration that put an end to Japan's feudal system in the late 19th century, the new government first requested to open a formal diplomatic and trade relationship with Korea. However, Korea declined the request and chose to remain within the sinocentric regime. Based on those cornerstones, a political debate has risen in Japan whether and how to force Korea to accept Japan's request, which was then expanded into Imperialism over neighboring Asian countries such as China and Russia. The First Sino-Japanese War (1894-96) and the Russo-Japanese War (1904-1905), both resulted in Japan's victory, were essentially the fight over the control of Korean peninsula.

After these victories, Imperial Japan began its colonial aggression to Korea and then to "Manchuria" (Northeast region of China) and finally to central China. In 1911, Imperial Japan "annexed" Korea, effectively colonized Korea under military force. Korean people started the protest against Japan, including "March 1st Movement" in 1919 with the proclamation of Independence in the center of the capital city of Seoul and demonstrations in many other locations, 7,500 were killed, 16,000 wounded, and 46,000 arrested by the Japanese ruler. ${ }^{48}$

Japan's aggression was finally terminated at the end of the World War II in 1945 and Korea reclaimed the independence, yet divided into North and South until today.

47 Malina Andreia Pal, The Japanese invasions of Korea: who was the real winner of the Imjin war? January 2020, Geneva.

https://www.researchgate.net/publication/344072575_The_Japanese_invasions_of _Korea_who_was_the_real_winner_of_the_Imjin_war.

48 Park Eun-sik, “韓国独立運動の血史 The Bloody History of the Korean Independence Movement, (Heibonshya, 1972). 
It must also be noted that in the aftermath of the Kanto Great Earthquake in September 1923, more than 6,000 ethnic Koreans living in Tokyo metropolitan areas were horribly killed by Japanese militias. ${ }^{49}$ With some instigating languages in the martial law degree from the Interior Ministry, in addition to the local police and military troops, a wide range of civil members under the activities of resident association in local communities played a significant role of actual killings. ${ }^{50}$

\section{A.2. Post WW II situation of Korean residents in Japan}

There are more than half a million ethnic Zainichi Koreans living in Japan now. Most of them belong to the second, third or fourth generation of Koreans whose parents or ancestors came to Japan before the World War II. Many chose to migrate to earn better living, many more were "forced" to come for economic or military reasons. They were treated as the secondclass citizens and have not been awarded with an actual equal status to those of the Japanese.

After Japan was defeated by the Allies in 1945, a significant number of Koreans went back to their motherland, especially among those who were forced to come to Japan against their wills. However, some chose to remain in Japan or had gone back to Korea once but decided to return to Japan, in part due to the severe socio-economic situation of Korean Peninsula caused by the Korean War in the early 1950s. ${ }^{51}$

The political divide between south and north along the Military Demarcation Line (MDL) started in 1952 further added complication among the Korean residents and their communities in Japan. Many Korean families whose origins were in the northern part started to "return" to North Korea in the 1960s, as the Democratic People's Republic of Korea (DPRK), or North Korea, strongly demanded Japanese government to facilitate the return program. Many Korean residents remained skeptical to the propaganda made by the communist government and however decided not to move.

49 Ryangok Ku, Chapter 5 The Current Movement of Hate Speech, in Hate Speech in Japan (Cambridge: Cambridge University Press, 2021), 218.

50 Gang, Deogsang, "Kanto Daishinsai (Kanto Great Earthquake)", (Tokyo, Chuo-Koronsha, 1975).

51 Yasunori Ooba, "Zainichi Kankoku and Chosenjin (South and North Korean residents in Japan”, (Chuokoron Shinsha, 1993). 
The Japanese society at large has kept continuous discriminatory attitudes against Korean residents who were mostly kept outside the Japanese socio-economic system; received discriminatory treatments in education, healthcare and social welfare, employment, business opportunities to name a few.

The diplomatic relation between Japan and Korea, both south and north, has been tense, or counter-productive for many years, even after the Republic of Korea, or South Korea, restored their democracy. It also remained painful between North Korea and Japan even after Japan's Prime Minister Koizumi made a sudden visit to North Korea and shook hands with North Korea Leader Kim Jong-Il in 2002 and 2004.

The "Comfort women" issue during wartime had been the subject of diplomatic negotiations between two governments and the Japanese government made an official reflection and apology in 1996. In Korea, some victims and their supporters have taken the issue to court to demand compensation from the government of Japan under the Korean court. Both cases received judgement in favor of the plaintiffs, but the final solution is still uncertain.

These historical contexts affect the complex relationship and bitter sentiments between Koreans and Japanese. With all these social, economic, and political complications, it is the author's persuasion that the Japanese society never embraced the Korean residents in a warm and civil manner in full.

It should be also noted that the relationship of both countries, especially between their citizens is not entirely negative. There have been many cases where they communicate and collaborate with and respect each other very well. There still is a good basis to build a better world in the East Asia. 
